\title{
Standoff Detection: Distinction of Bacteria by Hyperspectral Laser Induced Fluorescence
}

\author{
Arne Walter*a , Frank Duschek ${ }^{\mathrm{a}}$, Lea Fellner ${ }^{\mathrm{a}}$, Karin Grünewald ${ }^{\mathrm{a}}$, Anita Hausmannª, Sandra Julich ${ }^{\mathrm{b}}$, \\ Carsten Pargmann ${ }^{\mathrm{a}}$, Herbert Tomaso ${ }^{\mathrm{b}}$, Jürgen Handke ${ }^{\mathrm{a}}$ \\ ${ }^{a}$ Institute of Technical Physics, German Aerospace Center, Langer Grund, 74239 Hardthausen, \\ Germany; ${ }^{b}$ Friedrich-Loeffler-Institut, Institute of Bacterial Infections and Zoonoses, Naumburger \\ Strasse 96a, 07743 Jena, Germany
}

\begin{abstract}
Sensitive detection and rapid identification of hazardous bioorganic material with high sensitivity and specificity are essential topics for defense and security. A single method can hardly cover these requirements. While point sensors allow a highly specific identification, they only provide localized information and are comparatively slow. Laser based standoff systems allow almost real-time detection and classification of potentially hazardous material in a wide area and can provide information on how the aerosol may spread. The coupling of both methods may be a promising solution to optimize the acquisition and identification of hazardous substances.

The capability of the outdoor LIF system at DLR Lampoldshausen test facility as an online classification tool has already been demonstrated. Here, we present promising data for further differentiation among bacteria. Bacteria species can express unique fluorescence spectra after excitation at $280 \mathrm{~nm}$ and $355 \mathrm{~nm}$. Upon deactivation, the spectral features change depending on the deactivation method.
\end{abstract}

Keywords: Bacteria; Fluorescence, laser induced; Spectroscopy; Standoff detection; Biological sensing and sensors; Hazardous material; Biological agent

\section{INTRODUCTION}

Terrorist attacks with the neurotoxin sarin in the Tokyo subway in $1995^{1}$ and anthrax letters in $2001^{2}$ as well as accidental shipment of infectious anthrax contaminated material in 2015 show the need for an effective and fast solution to detect chemical and biological hazardous substances.

Quick identification and in cases of airborne agents localization of any released hazardous material is important to initiate appropriate counteractions. Bio agents are a particular threat to public health, because they are inexpensive, relatively easy to obtain, replicate and disseminate, while detection methods are complicated and time consuming. Due to the delay between infection and symptoms and the possibility of person to person spread, fast detection of potentially infectious bio agents is crucial for protection and immediate containment measures.

\subsection{Laser Induced Fluorescence}

Laser based standoff detection of hazardous material can be performed from safe distances to monitor wide areas up to the kilometer range in real-time. Established spectroscopic techniques for bio organics detect either scattered light $\left(\right.$ Raman $\left.^{3}\right)$, plasma emission $\left(\right.$ LIBS $\left.^{3,4}\right)$ or laser induced fluorescence $\left(\right.$ LIF $\left.^{3,5}\right)$. Among them LIF provides a high response signal at moderate excitation energies with limited spectral features. Utilization of several excitation wavelengths and time resolved measurements yields additional information and greatly improves discrimination especially when combined with sophisticated data analysis. To date, the combination of fast LIF-based detection, classification and localization of potential hazards and the subsequent guided acquisition and identification of samples seems to be a promising solution.

*arne.walter@dlr.de; phone +496298 28 636; dlr.de

Chemical, Biological, Radiological, Nuclear, and Explosives (CBRNE) Sensing XVII, edited by Augustus Way Fountain III, Proc. of SPIE Vol. 9824, 98240Y · (c) 2016 SPIE · CCC code: 0277-786X/16/\$18 · doi: 10.1117/12.2223769 
Operating a LIF system outdoors is challenging, because pollen, dust and diesel in the environment have to be taken into account. Fog, rain or snow affect laser propagation and scatter light while incident sunlight and ambient light interfere with the measurement. For use in inhabited areas, the laser radiation has to be eye safe.

\subsection{Fluorescence in Bacteria}

Compared to chemicals or even plant material, spectroscopy on bacteria is complicated due to the differences in size and shapes. Bacteria can occur as single cells, but they also form e.g. clusters, chains, or microfilms. Bacteria adapt to nutrient supply and other environmental conditions and change their metabolic activity accordingly ${ }^{6}$. Exposed to stress, some, like Bacillus anthracis, can reversibly form highly resistant dormant structures called endospores ${ }^{7}$. For Escherichia coli (E.coli), Hill et al. have described fifteen potential contributors to the overall fluorescence with tryptophan being the main source of fluorescence upon excitation at $280 \mathrm{~nm}^{8}$. An overview of involved fluorophores together with relevant absorption coefficients, mass fractions and estimated fluorescent quantum yields is given in Table 1. Since absorption ratios at $280 \mathrm{~nm}$ and $355 \mathrm{~nm}$ vary significantly for most shown fluorescing molecules, different sets of molecules will be probed. Promising results of a first advance in this field are presented in Ref. 9 as depicted in Figure 2. Here, we demonstrate recent advances in distinguishing different low hazard bacteria (as simulants for highly pathogenic bacteria) by their LIF signature and hence the possibilities for more detailed classification.

Table 1. Overview of the main fluorescing compounds for E.coli with spectral characteristics summarized from the work of Hill et al. ${ }^{8}$ and resulting estimated contribution to the overall fluorescence. Mass fractions for a mixture of closely related species from the genus Bacillus are set in parenthesis for comparison. $\varepsilon$ is the decadic molar attenuation coefficient. Note that quantum yields are highly dependent on the local environment of a fluorophore and may vary in magnitudes. *calculated from given values

\begin{tabular}{|c|c|c|c|c|c|c|}
\hline \multirow[t]{2}{*}{ Substance } & \multirow{2}{*}{$\begin{array}{l}\varepsilon\left(280 \mathrm{~nm}^{-1}\right. \\
1 \mathrm{~mol}^{-1} \mathrm{~cm}^{-1}\end{array}$} & \multirow{2}{*}{$\begin{array}{l}\varepsilon(355 \mathrm{~nm}) \\
1 \mathrm{~mol}^{-1} \mathrm{~cm}^{-1}\end{array}$} & \multirow{2}{*}{$\begin{array}{c}\text { Mass } \\
\text { fraction } \\
\mathrm{g} / \mathrm{g} \text { dry } \\
\text { weight }(\%)\end{array}$} & \multicolumn{3}{|c|}{ Fluorescence } \\
\hline & & & & $\begin{array}{l}\text { Quantum } \\
\text { Yield }\end{array}$ & $\begin{array}{c}\text { Calculated } \\
\text { contribution at } \\
280 \mathrm{~nm}^{(\%)}{ }^{*}\end{array}$ & $\begin{array}{c}\text { Calculated } \\
\text { contribution at } \\
355 \mathrm{~nm}(\%)^{*}\end{array}$ \\
\hline Tryptophan & 5800 & 0 & $1.1(4.0)$ & 0.12 & 95.9 & 0.0 \\
\hline Tyrosine & 1400 & 0 & $2.3(3.5)$ & 0.003 & 1.4 & 0.0 \\
\hline Phenylalanine & 70 & 0 & $2.9(4.0)$ & 0.001 & 0.0 & 0.0 \\
\hline $\begin{array}{l}\text { NADH } \\
+ \text { NADPH }\end{array}$ & 2500 & 5200 & $\begin{array}{l}0.048 \\
(0.058)\end{array}$ & 0.04 & 0.2 & 27.1 \\
\hline $\begin{array}{l}\text { Riboflavin } \\
+ \text { FMN }\end{array}$ & 5000 & 9000 & $\begin{array}{l}0.011 \\
(0.01)\end{array}$ & 0.13 & 0.5 & 58.6 \\
\hline FAD & 30000 & 9000 & $\begin{array}{l}0.045 \\
(0.045)\end{array}$ & 0.013 & 0.6 & 11.7 \\
\hline $\begin{array}{l}\text { Pyridoxal } \\
\text { derivates } \\
\text { (unbound) }\end{array}$ & $\begin{array}{l}1000- \\
2200\end{array}$ & $0-800$ & $\begin{array}{l}0.012 \\
(0.012)\end{array}$ & $0.01-0.14$ & 0.1 & 2.6 \\
\hline $\begin{array}{l}\text { Pyridoxal } \\
\text { derivates bound }\end{array}$ & 1000 & $\begin{array}{l}1400- \\
4800\end{array}$ & $\begin{array}{l}0.008 \\
(0.008)\end{array}$ & $\begin{array}{l}0.002- \\
0.008\end{array}$ & 0.0 & 0.0 \\
\hline Ubiquinol & 40000 & 0 & $0.003(0.0)$ & 0.018 & 0.1 & 0.0 \\
\hline Menaquinol & 2700 & 6000 & $\begin{array}{l}0.001 \\
(0.003)\end{array}$ & 0.27 & 0.0 & 0.10 \\
\hline
\end{tabular}




\section{EXPERIMENTAL SETUP}

\subsection{Optical setup}

To meet the challenges of outdoor detection, the standoff LIF detection system used for the shown measurements is operated on a free space optical test range at the German Aerospace Center at Lampoldshausen. CBE substances can be measured at distances from 20 to $135 \mathrm{~m}$ under different weather conditions. Laser and detection system are located in a cabin whereas the target is positioned outdoors. While experiments can be carried out with both aerosols and liquid phase in a cuvette at a range of distances, all data shown here were collected for suspensions at a distance of $22 \mathrm{~m}$.

Eye safe laser pulses at $280 \mathrm{~nm}$ and $355 \mathrm{~nm}$ are used to excite the sample. Time-resolved spectra are captured by a gated iCCD camera. The detection system is prepared for background correction and trained pattern recognition software that classifies the sample into coarse classes.

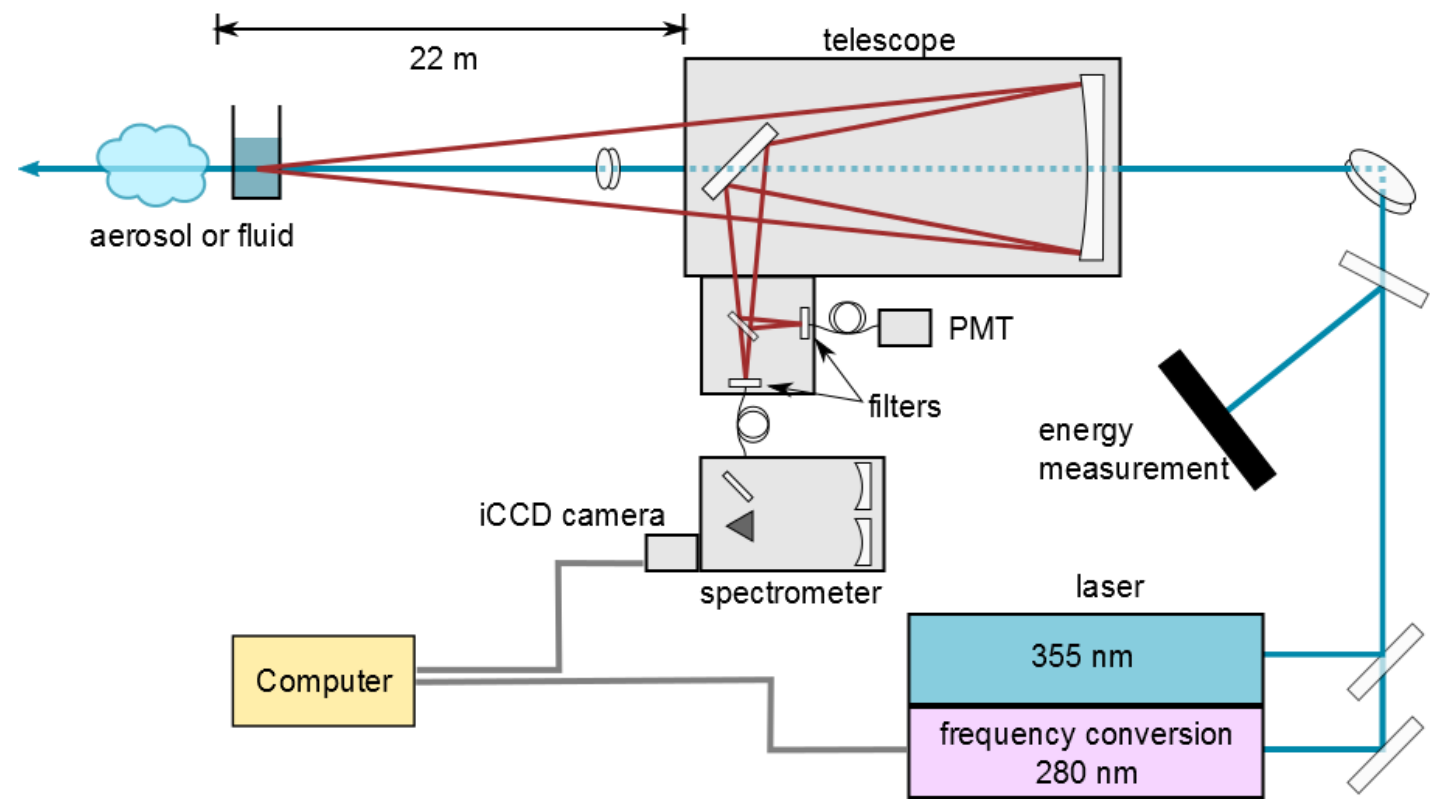

Figure 1. Schematic draft of the optical setup ${ }^{5}$.

The schematic setup of the detection system is shown in Figure 1. A Nd:YAG laser supplies pulses of 7 ns pulse length at $355 \mathrm{~nm}$ with a repetition rate of $10 \mathrm{~Hz}$. Each second pulse is frequency converted to $280 \mathrm{~nm}$, resulting in an effective repetition rate of $5 \mathrm{~Hz}$ with pulse energies of about $10 \mathrm{~mJ}$ for each wavelength. Both wavelengths are guided onto the target. Fluorescence light is collected by a Newton telescope with an optical diameter of $400 \mathrm{~mm}$. The collected light is split, spectrally filtered to suppress the laser lines and coupled into optical fibers. One fraction is detected by a photomultiplier tube (PMT) providing information on the wavelength-independent time signal of the fluorescence. The other fraction is analyzed by a spectrometer with a resolution of $1 \mathrm{~nm}$ and a spectral range of $300-600 \mathrm{~nm}$ and captured by a gated iCCD camera. Time resolved spectra are obtained by combination of several consecutive measurements with camera gates delayed relative to the laser pulse. Well after each laser pulse, a background spectrum is recorded to compensate for fluctuations in background radiation and to make measurements more independent from weather conditions. A detailed description of the optical and electronical setup and more details on data acquisition and processing is given in Reference 5.

\subsection{Cultivation and Sample preparation}

Bacterial strains: Bacillus thuringiensis var. kurstaki strain HD-1 (isolated from insecticide DIPEL), Escherichia coli K12 ${ }^{10}$, Bacillus atrophaeus Nakamura 1989 (DSM 7264) and Bacillus subtilis (DSM 1970). 
Cultivation of the bacteria species was carried out on blood agar plates (nutrient agar 1 obtained by Sifin, Berlin, Germany) supplemented with $7.5 \%$ cattle or sheep blood at $37^{\circ} \mathrm{C}$ for $24 \mathrm{~h}$. Colony material was harvested and suspended in phosphate buffered saline (PBS) and stored at $4{ }^{\circ} \mathrm{C}$. The concentration of colony forming units (CFU) per $\mathrm{ml}$ was determined by cultivation of $100 \mu \mathrm{l}$ serially diluted solution in PBS with $0.4 \%$ agar on agar plates at identical conditions. Bacterial suspensions were diluted with PBS to the concentrations measured. Chemical samples (NADH, amino acids) were solved in deionized water, stirred for $1 \mathrm{~h}$ and stored at $4{ }^{\circ} \mathrm{C}$ over night. Deactivation of bacteria was carried out either by heating at $95{ }^{\circ} \mathrm{C}$ for $10 \mathrm{~min}$, autoclaving at $134{ }^{\circ} \mathrm{C}$ for $30 \mathrm{~min}$, dilution in Ethanol and gamma radiation at $30 \mathrm{kGy}+/-10 \%$ (done by Synergy Health Radeberg GmbH, Radeberg, Germany).

\section{RESULTS}

\subsection{Bacteria Spectra}
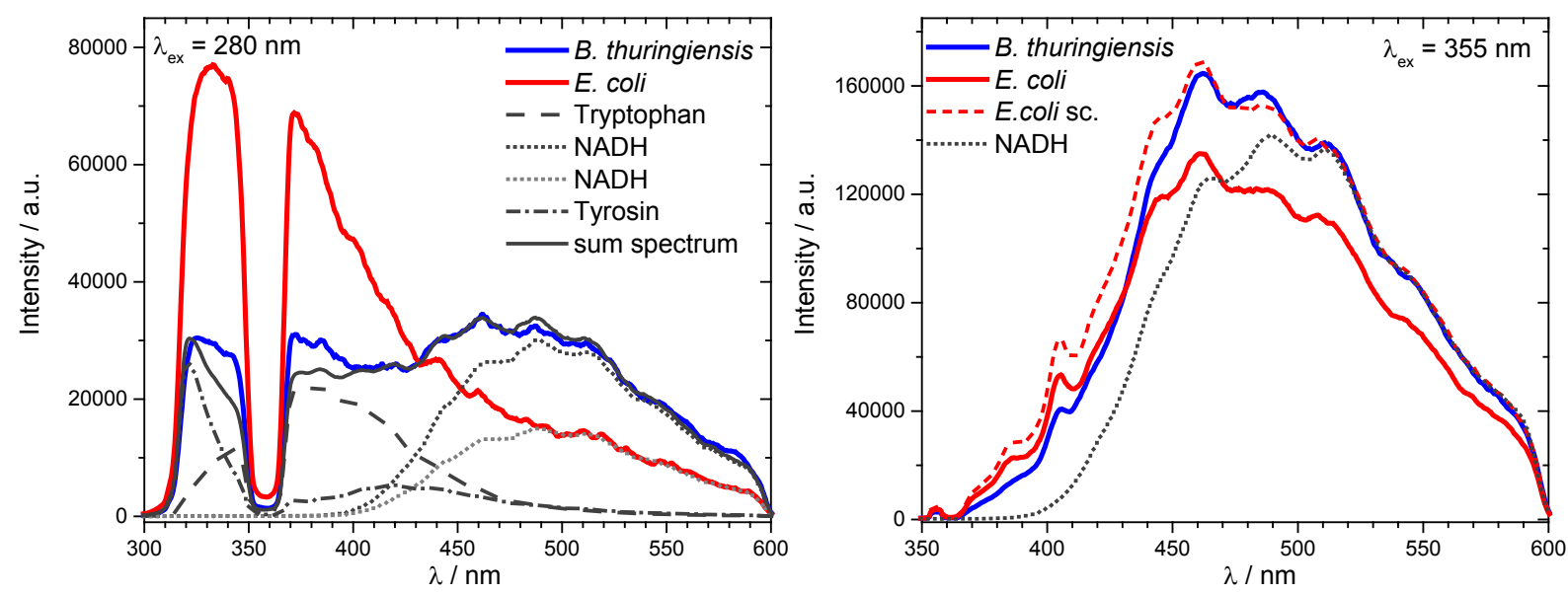

Figure 2. LIF spectra of B. thuringiensis $\left(10^{7} \mathrm{CFU} / \mathrm{ml}\right.$ in PBS) and E.coli $\left(10^{9} \mathrm{CFU} / \mathrm{ml}\right.$ in PBS) upon excitation at $280 \mathrm{~nm}$ (left) and $355 \mathrm{~nm}$ (right). E. coli spectrum at $355 \mathrm{~nm}$ is scaled for comparison (dashed red line). On the left panel, fluorescence spectra of tryptophan, NADH and tyrosine and the sum of those spectra are plotted (dashed, dotted, dashdotted and solid grey line), scaled to tentatively fit B.thuringiensis. On the right panel, only NADH is plotted (dotted grey line). All spectra are corrected for solvent-contributions.

Figure 1 presents LIF spectra of the bacteria Bacillus (B.) thuringiensis and Escherichia (E.) coli, upon excitation at $280 \mathrm{~nm}$ and $355 \mathrm{~nm}$. At $355 \mathrm{~nm}$, both spectra express similar features. For wavelengths above $500 \mathrm{~nm}$, they are practically identical, backed by the scaled spectrum of E.coli (dashed red line) superimposed to B. thuringiensis (blue line). Following the findings in Table 1, only few components should contribute to the observed fluorescence. For wavelengths above $500 \mathrm{~nm}$, the spectral features coincide with pure NADH (dotted grey line). Below $500 \mathrm{~nm}$, the bacteria spectra differ slightly. In contrast, the bacteria spectra at $280 \mathrm{~nm}$ can be easily distinguished. Here, E. coli (red line) shows a strong fluorescence signal between $300 \mathrm{~nm}$ and $450 \mathrm{~nm}$, whereas $B$. thuringiensis has a broader, less pronounced signal (blue line). Below $500 \mathrm{~nm}$, dominant fluorophores should be mainly tryptophan (emission spectrum shown as dashed grey line) and some tyrosine (dash-dotted grey line). We tentatively added the fluorescence spectra of these amino acids (solid grey line) to reproduce $B$. thuringiensis emission. For wavelengths above $400 \mathrm{~nm}$, this worked surprisingly well. While Table 1 suggests a higher relative tryptophan concentration for the Bacillus species, in the measured spectra its contribution to fluorescence seems less compared to E.coli. Above $500 \mathrm{~nm}$, both bacteria spectra coincide with NADH emission (dotted grey lines). While at $355 \mathrm{~nm}$ excitation wavelength, fluorescence intensity was similar around $500 \mathrm{~nm}$, excited at $280 \mathrm{~nm}$ E.coli fluoresces significantly less. One issue in this matter will be absorption and reabsorption. Though only few molecules within a bacterium contribute to fluorescence ${ }^{8}$, others will absorb light and not every potentially fluorescing molecule will be reached. To be detected, the emitted light will have to travel back to the source of the light. Since it will be redshifted compared to the excitation wavelength, it is expected to be partially absorbed. Therefore, measured bacteria spectra will rarely be just the sum of their components' spectra. Another issue is 
each molecule's fluorescence quantum yield, which can vary by several magnitudes depending on the local environment ${ }^{11}$. The quantum yields found for molecules in solution can be a hint at best.

However, our main concern is to distinguish between different bacteria. This objective is clearly achieved for $B$. thuringiensis and E.coli. These bacteria are only very distant relatives in the domain of bacteria. Close relatives might express very similar spectra. To understand the capabilities and limitations of LIF based discrimination of bacteria, we have selected additional representatives of the genus Bacillus, i.e. Bacillus subtilis and Bacillus atrophaeus. An overview of the phylogenetic relationships is presented in Figure 3; corresponding LIF spectra are shown in Figure 4.

\begin{tabular}{|c|c|c|c|c|}
\hline domain & & & Bacteria & \\
\hline phylum & & Firmicutes & & Protobacteria \\
\hline class & & Bacilli & & Gamma-Proteobacteria \\
\hline order & & Bacillales & & \\
\hline family & & Bacillaceae & & Enterobacteriaceae \\
\hline genus & & Bacillus & & Escherichia \\
\hline species & B. atrophaeus & B. thuringiensis & B. subtilis & E. coli \\
\hline
\end{tabular}

Figure 3. Phylogenetic tree showing evolutionary relations between species investigated in this study based on their genetic characteristics.

When exited at $280 \mathrm{~nm}$, fluorescence of B. subtilis (green solid line) and B. atrophaeus (yellow solid line) show similar spectral features compared to $B$. thuringiensis (blue solid line), e.g. a broad spectra and a strong emission in the region above $450 \mathrm{~nm}$. Scaled to fit the spectral region above $500 \mathrm{~nm}$, spectral differences become more obvious. While at $280 \mathrm{~nm}$, emission intensities for the selected bacteria are in a similar range. At $355 \mathrm{~nm}$, B. subtilis and B. atrophaeus show a significant lower emission. Scaling of the spectra (dashed lines) reveals that they are of similar shape as the spectra of B. thuringiensis.
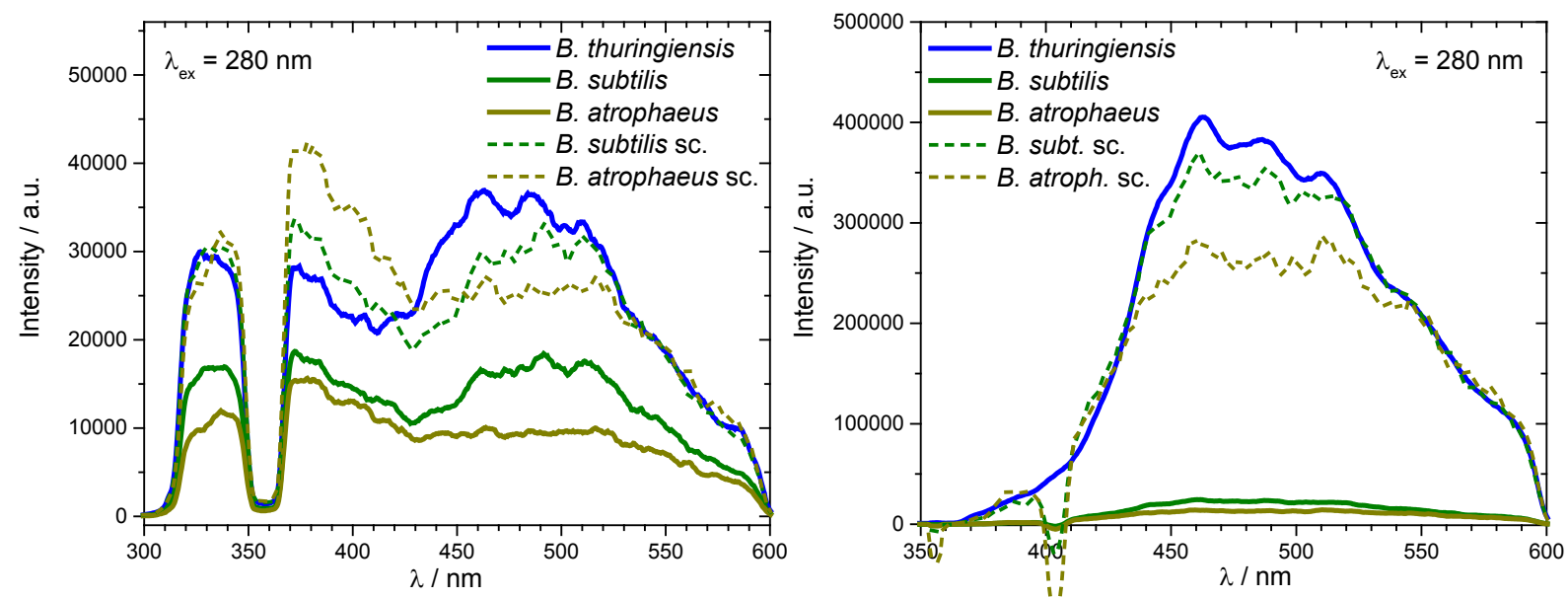

Figure 4. Fluorescence spectra of B. thuringiensis, B. subtilis and B. atrophaeus $\left(10^{8} \mathrm{CFU} / \mathrm{ml}\right.$ in PBS) upon excitation at $280 \mathrm{~nm}$ (left) and $355 \mathrm{~nm}$ (right). Dashed curves are scaled to fit the spectrum of B. thuringiensis on the red flank for comparison. Spectra are smoothed and corrected for solvent-interactions.

\subsection{Deactivation}

For proof of principle, LIF standoff detection for classification and identification of bacteria was evaluated using nonhazardous bacterial species as simulants for highly pathogenic bacteria. Further evaluations will have to be performed 
also with hazardous species under biosafety level 2 and 3 conditions in aerosol chambers to create a database that allows differentiation among bacterial genera or even species.

However, it would facilitate the experimental approach, if inactivated bacteria show the same fluorophores as living bacteria and time-consuming and potentially dangerous work with highly pathogenic bacteria might be reduced or completely avoided. Therefore, LIF spectra of $B$. thuringiensis that was inactivated using different treatments were compared. Upon heating to $95^{\circ} \mathrm{C}$, the $280 \mathrm{~nm}$ spectrum shows minor changes, namely a decrease below and a minor increase above $350 \mathrm{~nm}$. The $355 \mathrm{~nm}$ spectrum remains almost unchanged. Autoclaved, the spectra show similar changes with a larger increase in overall fluorescence intensity. Treated with ethanol, the $280 \mathrm{~nm}$ spectrum remains unchanged above $400 \mathrm{~nm}$ but fluorescence below significantly increases. The $355 \mathrm{~nm}$ spectrum also expresses an increase for wavelengths below $500 \mathrm{~nm}$. Irradiation with gamma rays results in the most drastic changes in the fluorescence spectra. Excitation at $280 \mathrm{~nm}$ induces hardly any fluorescence below $350 \mathrm{~nm}$ but an increased emission for longer wavelengths. Excited at $355 \mathrm{~nm}$, fluorescence is increased for all observed wavelengths.

The pronounced spectral fluorescence changes for both excitation wavelengths upon gamma irradiation and ethanol treatment basically rule out these methods of deactivation for preparation of optical facsimiles. However, upon both, heating to $95^{\circ} \mathrm{C}$ and autoclaving, the spectral changes are quite small for $280 \mathrm{~nm}$ spectra and negligible at $355 \mathrm{~nm}$. Whether these differences are within the tolerances of a specifically trained classifier has yet to be tested.
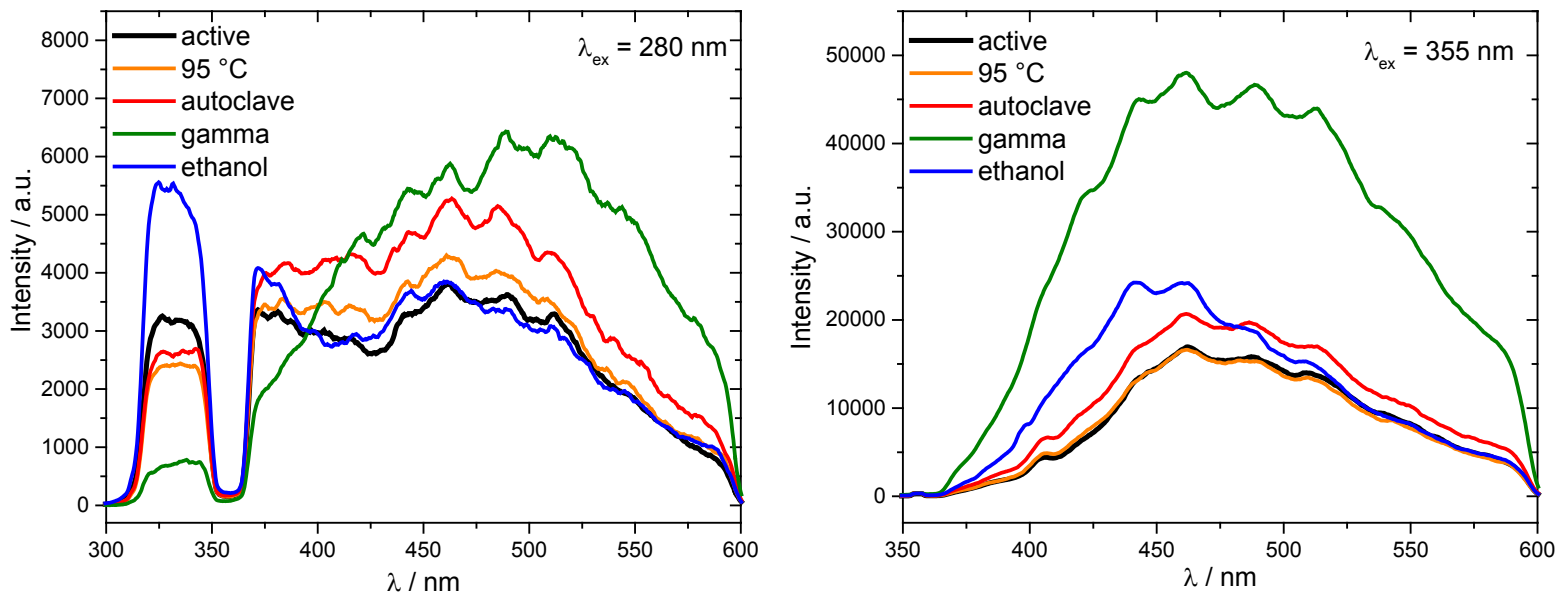

Figure 5. LIF spectra of $B$. thuringiensis after deactivation by different methods.

\section{CONCLUSION AND OUTLOOK}

Hyperspectral LIF standoff spectra of very distant relatives of bacteria as well as of closely related species have been shown for UV wavelengths. The spectral diversity even within three species of a genus was proven to be high enough for safe distinction. It was shown that inactivation methods can have influences on the spectra of $B$. thuringiensis. Spectral accordance of some fluorophores with parts of the bacteria spectra has been illustrated.

As an outlook, an extension of the classifier for more distinct classification up to identification on the species level is desirable and in perspective, the spectral database ${ }^{5,9}$ will be extended. Investigations in more detailed classification will be carried out. The use of inactivated bacteria for safe handling of hazardous species will be investigated further by applying more methods on a range of species. Also, we will have a closer look on the spectral contributions of bacteria fluorophores. 


\section{REFERENCES}

[1] Tu, A. T., "Overview of Sarin Terrorist Attacks in Japan," [ACS Symposium Series], A. T. Tu and W. Gaffield, Eds., American Chemical Society (ACS), 304-317 (1999).

[2] Council, N. R., [Review of the Scientific Approaches Used During the FBI Investigation of the 2001 Anthrax Letters], The National Academies Press (2011).

[3] Wallin, S., Pettersson, A., Östmark, H., Hobro, A., "Laser-based standoff detection of explosives: a critical review," Anal Bioanal Chem 395(2), 259-274, Springer Science mathplus Business Media (2009).

[4] Duschek, F., Pargmann, C., Grünewald, K., Handke, J., "Stand-off detection at the DLR laser test range applying laser-induced breakdown spectroscopy," Optics and Photonics for Counterterrorism and Crime Fighting VI and Optical Materials in Defence Systems Technology VII, C. Lewis, D. Burgess, R. Zamboni, F. Kajzar, and E. M. Heckman, Eds., SPIE-Intl Soc Optical Eng (2010).

[5] Fischbach, T., Duschek, F., Hausmann, A., Pargmann, C., Aleksejev, V., Poryvkina, L., Sobolev, I., Babichenko, S., Handke, J., "Standoff detection and classification procedure for bioorganic compounds by hyperspectral laser-induced fluorescence," Chemical, Biological, Radiological, Nuclear, and Explosives (CBRNE) Sensing XVI, A. W. Fountain, Ed., SPIE-Intl Soc Optical Eng (2015).

[6] Abee, T., Wouters, J. A., "Microbial stress response in minimal processing," International Journal of Food Microbiology 50(1-2), 65-91, Elsevier BV (1999).

[7] Koehler, T. M., "Bacillus anthracis physiology and genetics," Molecular Aspects of Medicine 30(6), 386-396, Elsevier BV (2009).

[8] Hill, S. C., Pan, Y.-L., Williamson, C., Santarpia, J. L., Hill, H. H., "Fluorescence of bioaerosols: mathematical model including primary fluorescing and absorbing molecules in bacteria," Opt. Express 21(19), 22285, The Optical Society (2013).

[9] Duschek, F., Fischbach, T., Hausmann, A., Pargmann, C., Thieser, J., Julich, S., Aleksejev, V., Poryvkina, L., Sobolev, I., et al., "A fast Hyperspectral Laser Induced Fluorescence application for standoff detection and online classification of biological hazardous materials," 10th Future Security 2015. Security Research Conference. Proceedings 10, 97-104, Stuttgart Fraunhofer Verlag, Berlin (2015).

[10] Clowes, R. C., Hayes, W., [Experiments in microbial genetics], R. C. Clowes and W. Hayes, Eds., Blackwell Scientific Publications (1968).

[11] Pan, C.-P., Barkley, M. D., "Conformational Effects on Tryptophan Fluorescence in Cyclic Hexapeptides," Biophysical Journal 86(6), 3828-3835, Elsevier BV (2004). 